$11-21-2016$

\title{
Secretory paraspinal paraganglioma of thoracolumar spine: Case report and review of literature
}

\author{
Saad Akhtar \\ Aga Khan University \\ Sidra Sattar \\ Aga Khan University, sidra.sattar@aku.edu \\ Muhammad Ehsan Bari \\ Aga Khan University, ehsan.bari@aku.edu \\ Naila Kayani \\ Aga Khan University, naila.kayani@aku.edu \\ Sarosh Moeen \\ Aga Khan University
}

Follow this and additional works at: https://ecommons.aku.edu/pakistan_fhs_mc_surg_neurosurg

Part of the Neurology Commons, Neurosurgery Commons, Pathology Commons, and the Surgery

Commons

\section{Recommended Citation}

Akhtar, S., Sattar, S., Bari, M., Kayani, N., Moeen, S. (2016). Secretory paraspinal paraganglioma of thoracolumar spine: Case report and review of literature. Surgical Neurology International, 7(Suppl 37), S889-S892.

Available at: https://ecommons.aku.edu/pakistan_fhs_mc_surg_neurosurg/88 


\title{
Case Report
}

\section{Secretory paraspinal paraganglioma of thoracolumar spine: Case report and review of literature}

\author{
Saad Akhtar, Sidra Sattar, Ehsan Bari, Naila Kayani ${ }^{1}$, Sarosh Moeen ${ }^{1}$ \\ Departments of Neurosurgery, ${ }^{1}$ Histopathology, Aga Khan University Hospital, Karachi, Pakistan \\ E-mail: Saad Akhtar - saad.akhtar@aku.edu; Sidra Sattar - sidra.sattar91@gmail.com; *Ehsan Bari - ehsan.bari@aku.edu; Naila Kayani - naila.kayani@aku.edu; \\ Sarosh Moeen - sarosh.moeen@aku.edu \\ *Corresponding author
}

Received: 20 January $16 \quad$ Accepted: 28 September $16 \quad$ Published: 21 November 16

\begin{abstract}
Background: Pheochromocytomas are catecholamine secreting tumors of the adrenal medulla chromaffin cells, however, when present extra-adrenally they are called paragangliomas. Paragangliomas rarely produce catecholamine in excess, which is evident by clinical symptoms, urine, and blood biochemistry. Total resection of these tumors can lead to complete clinical and biochemical resolution. This case report presents the clinical features, radiological findings, and neurological outcome in a middle-aged female with a secretory paraganglioma.

Case Description: We present the case of a 34-year-old female who presented with a 2-year history of dizziness, flushing, headache, palpitations, and hypertension. Her blood workup showed raised urinary catecholamine levels. Magnetic resonance imaging (MRI) and iodine-123-meta-iodobenzylguanidine (MIBG) scans demonstrated a retroperitoneal mass located anterolateral to T11-T12 vertebral bodies reaching up to T12-L1 intervertebral disc. The patient was otherwise neurologically intact. She underwent resection of the tumor after alpha-adrenergic and beta-adrenergic blockade. En bloc resection was achieved without neurological complications. Postoperatively, the patient was initially hypotensive and subsequently became normotensive, and on follow-up, the patient had resolution of her symptoms and was stable.

Conclusion: Secretory paraganglioma of the dorsal spine are rare and difficult to excise, needs preoperative preparation with pharmacological intervention, good operative technique, and postoperative care.

Key Words: Paraganglioma, paraspinal, secretory, thoracolumbar spine

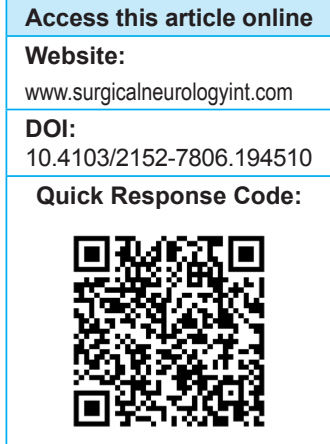

\section{INTRODUCTION}

Paraganglioma is an extra-adrenal pheochromocytoma which rarely present as a primary cause of hypertension caused by catecholamine excess. Paragangliomas mostly present as lumbosacral intradural tumors. ${ }^{[1,4]}$ Thoracic paraspinal lesions are distinctly unusual. We present a case of a functioning thoracic paraspinal paraganglioma in a woman who presented with symptoms of catecholamine excess.
This is an open access article distributed under the terms of the Creative Commons Attribution-NonCommercial-ShareAlike 3.0 License, which allows others to remix, tweak, and build upon the work non-commercially, as long as the author is credited and the new creations are licensed under the identical terms.

For reprints contact: reprints@medknow.com

How to cite this article: Akhtar S, Sattar S, Bari E, Kayani N, Moeen S. Secretory paraspinal paraganglioma of thoracolumar spine: Case report and review of literature. Surg Neurol Int 2016;7:S889-92.

http://surgicalneurologyint.com/Secretory-paraspinal-paraganglioma-ofthoracolumar-spine:-Case-report-and-review-of-literature/ 


\section{CASE PRESENTATION}

A 34 year old female presented with episodes of dizziness, flushing, headache, and palpitations since the last 2 years. The symptoms worsened on awakening, especially in the morning associated with leg cramps and mixed features of claudication that settled gradually over the day. The past medical history was significant for postpartum cardiomyopathy with an ejection fraction of $25 \%$. On general physical examination (GPE), she was a middle-aged female of average height and build with intact higher mental functions. Her vitals showed raised blood pressure episodes ranging 220-180/110-150 mmHg and tachycardia of $100-110 \mathrm{bpm}$ whereas the rest of the systemic examination was normal. Neurological examination was also unremarkable. Laboratory evaluation showed raised vanillylmandelic acid (VMA) (Serum VMA levels 16 mg/dl, Urinary VMA/24 h 2600 ml/24 h).

Magnetic resonance imaging of the abdomen including thoracolumbar spine with and without intravenous contrast [Figure 1] showed a retroperitoneal paraspinal mass measuring $46.0 \times 36 \mathrm{~mm}$ right crus of the diaphragm anterolateral to T11-T12 vertebral bodies reaching up to T12-Ll intervertebral disc. It appeared iso to hyperintense on Tl-weighted images, hyperintense on T2-weighted images, and showed heterogeneous contrast enhancement. It was closely abutting the abdominal aorta and displacing the IVC anteriorly. Bilateral adrenal glands appeared unremarkable.

Radionucleotide whole body imaging with I-123 MIBG scan showed abnormal uptake over the right adrenal

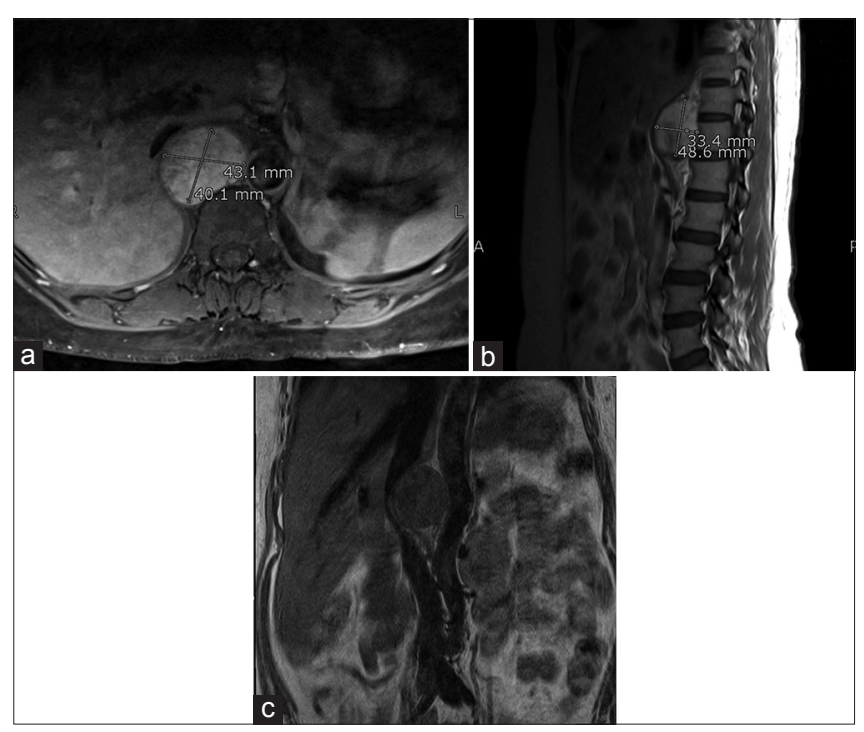

Figure I: (a) MRI spine sagittal cut T2 weighted showing hyperintense anteriorly placed paraspinal lesion extending from DI I to lower border of D I 2; (b) MRI spine axial cut post-contrast homogenous enhancement and close proximity with inferior vena cava (IVC); (c) MRI spine coronal cut showing lesion measuring $46.0 \times 36 \mathrm{~mm}$ closely abutting the abdominal aorta and is displacing the IVC anteriorly region. The patient was referred to an endocrinologist for preoperative optimization of blood pressure. She received alpha-blockade and beta-blockade before surgical resection. Because of the close proximity of the lesion with abdominal aorta and displacement of IVC, vascular surgery was done. A combined right-sided transthoracic transdiaphragmatic and retroperitoneal approach was made. The liver was mobilized to expose the IVC, and caudal dissection was performed to expose the tumor. Intraoperative findings included a well-circumscribed paraspinal lesion abutting the body of Dll and displacing the IVC anteriorly. The tumor capsule was freed of all bridging veins and was removed in total. Manipulation of the tumor produced hemodynamic instability and inotropes had to be started immediately after removal of the tumor. The postoperative course was unremarkable with no neurological deficit or complications. Previous concerns of raised blood pressure were addressed and the patient was discharged home; on follow-up, the patient has been recovering well.

The examination of gross surgical specimen [Figure 2] revealed a well-circumscribed, encapsulated nodular tissue measuring $5.5 \times 4.5 \times 3.5 \mathrm{~cm}$. Histopathological examination of the cut surface showed a brown appearance. Microscopic examination [Figure 3] revealed well-defined nests of cuboidal cells arranged in a "Zellballen" pattern which were separated by highly vascular fibrous septae. The individual cells had amphophilic granular cytoplasm and rounded nuclei with discernible nucleoli. Brown melanin pigment was also noted. Immunohistochemically, these tumor cells were positive for synaptophysin and chromogranin, whereas S-100 protein stained the sustentacular cells, yielding a diagnosis of paraganglioma.

\section{DISCUSSION}

Pheochromocytoma is a benign tumor (malignancy rate of $10-15 \%$ ) which arises from chromaffin cells with

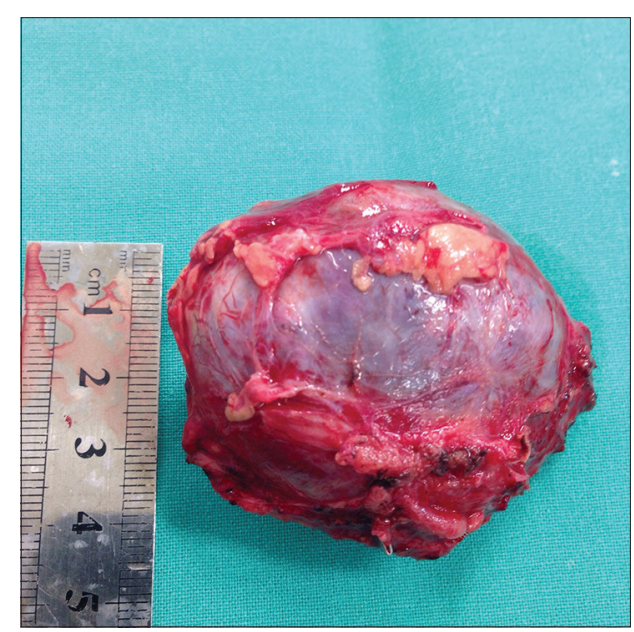

Figure 2: Well-circumscribed, encapsulated nodular tissue measuring $5.5 \times 4.5 \times 3.5 \mathrm{~cm}$ 
excessive catecholamine production and secretion. Most tumors are localized in the adrenals $(85-90 \%),{ }^{[11]}$ however, $15-18 \%$ of the lesions are found extraadrenally. ${ }^{[8]}$

Pheochromocytoma should be considered as a differential in the evaluation of hypertension, arrhythmias, or panic disorder in young individuals, as well as in the follow-up of patients with particular genetic diseases. ${ }^{[3]}$

Symptomatology secondary to catecholamine excess includes hypertension (either sustained or episodic in nature), headache, palpitations, sweating, and weight loss. ${ }^{[15]}$

Extra-adrenal pheochromocytomas of the neural crest derived sympathetic ganglia are known as paragangliomas. ${ }^{[5]}$

The initial diagnosis was based on the metabolites found in the serum and urine. Biochemically, elevated levels of one or more of the catecholamine metabolites are noted in the blood or urine on initial screening test performed in a clinically suspected case. ${ }^{[15,12]}$ The sensitivity of plasma metanephrine levels has been reported to be as high as $100 \%$ compared with $82 \%$ for urinary and plasma catecholamine levels $(P<0.005){ }^{[8]}$

Shin et al. in his case series on spinal paragangliomas summarized MR findings as relatively well defined mass with low-to-intermediate signal intensity on Tl-weighted

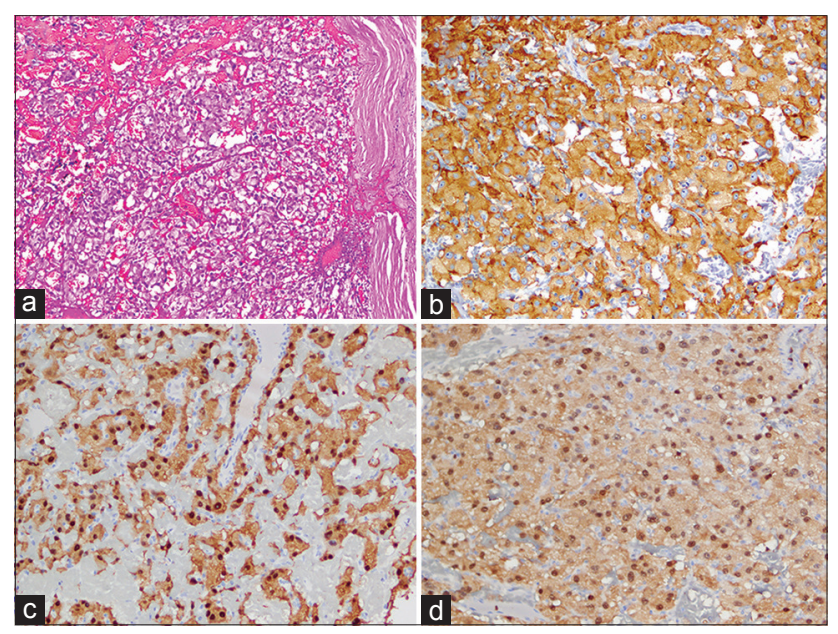

Figure 3: (a) Hematoxylin and eosin stained section (Original magnification $\times 10$ ) showing well-defined nests of cuboidal cells having granular cytoplasm, separated by highly vascular septae. (b) tumor cells show cytoplasmic staining for Immunohistochemical stain synaptophysin (Original magnification $\times 20$ ); (c) immunohistochemical stain chromogranin, positive in cytoplasm of tumor cells. (Original magnification $\times 20$ ); (d) Immunohistochemical stain S-100. (Original magnification $\times 20$ ) images and intermediate to high signal intensity on T2-weighted images compared to paravertebral muscles. Contrast-enhanced MR images showed intense heterogeneous enhancement, ${ }^{[7,14,16]}$ which was similar to our findings.

Paragangliomas have distinctive histological features. Clusters of large polyhedral chief cells are arranged in nests (Zellballen) surrounded by a delicate fibrovascular stroma. The tumor cells exhibit granular eosinophilic cytoplasm and round or ovoid nuclei. There is positive staining for synaptophysin, chromogranin, S-100, and tumor-specific antigen. Malignancy cannot be determined with histological assessments, but is demonstrated by metastases and invasion. ${ }^{[7]}$

Preoperative preparation includes administration of at least 2 weeks with an alpha blockade such as phenoxybenzamine in addition to a beta blockade. This is recommended to prevent consequences of catastrophic chronic vagal tone suppression during surgery. ${ }^{[13]}$ Our patient underwent similar preparation.

Spinal paraganglioma are rare, with approximately 90 cases reported in the literature. ${ }^{[2]}$ Only eight cases of thoracic primitive non-secretory paraspinal paragangliomas have been reported in the literature. ${ }^{[1,3-6,9,10,14]}$ To the best of our knowledge, only two cases of thoracic paraspinal secretory ones has been reported and this is the third reported case in the available literature.

Review of the literature [Table 1] shows two cases of thoracic paraspinal secretary paraganglioma. Graham et al. ${ }^{[5]}$ reported a case of a 53-year-old female with a tumor within T12 vertebra and elevated urinary cathecholamine metabolites. Similarly, Spector et al. ${ }^{[15]}$ demonstrated another case of a biochemically active paraganglioma presenting as a posterior mediastinal mass in an 8-year-old boy.

We present a similar case of functionally active thoracic paraganglioma in a 36-year-old female who presented with sympathomimetic features and raised urinary catecholamine metabolites, which resolved after complete surgical excision of the paraganglioma suggesting a cure from the primary etiology.

\section{CONCLUSION}

Paragangliomas should be considered as an etiology when treating hypertension in young patients, though

Table 1: Literature review in functioning paragangliomas

\begin{tabular}{|c|c|c|c|c|c|c|c|}
\hline Year & Author & Sex & Age & Location & Signs/Symptoms & Surgical treatment & Follow-up \\
\hline 2003 & Graham JJ et al. & Female & 53 & $\mathrm{~T} 12$ & $\begin{array}{l}\text { headaches, facial flushing, } \\
\text { and palpitations }\end{array}$ & Total & Normotensive, no neurological deficits \\
\hline 2003 & Spector JA et al. & male & 8 & T1-T5 & $\begin{array}{l}\text { headache, erythema, and } \\
\text { swelling of the hands }\end{array}$ & Total & Normotensive, no neurological deficits \\
\hline
\end{tabular}


being rare can provide excellent postoperative results after complete resection and an uneventful operative course.

\section{Financial support and sponsorship}

Nil.

\section{Conflicts of interest}

There are no conflicts of interest.

\section{REFERENCES}

I. Boker DK, Wassmann H, Solymosi L. Paragangliomas of the spinal canal. Surg Neurol 1983; 19:461-8.

2. Cotran R, Kumar V, Collins T. The endocrine system, In: Robbins Pathologic Basis of Disease. Sydney: Saunders, Inc; 1999. p. II64-6.

3. Cybulski GR, Nijenshon E, Brody BA, Meyer PR, Cohen B. Spinal cord compression from a thoracic paraganglioma: Case report. Neurosurgery 1991;28:306-9.

4. Fitzgerald LF, Cech DA, Goodman JC. Paraganglioma of the thoracic spinal cord: Case report. Clin Neurol Neurosurg 1996;98:183-5.

5. Graham JJ, Lee GY, Wong GT. Functioning paraganglioma of the thoracic spine: Case report. Neurosurgery 2003;53:992-5.

6. Houten JK, Babu RP, Miller DC. Thoracic paraganglioma presenting with spinal cord compression and metastases. J Spinal Disord Tech 2002;15:319-23.
7. Kleiwer K, Cochran A. A review of the histology, ultrastructure, immunochemistry and molecular biology of extra-adrenal paragangliomas. Arch Pathol Lab Med 1989; I 13:1209-18.

8. Lenz T, Gossman J, Schulte KL, Salewski L, Geiger H. Diagnosis of pheochromocytoma. Clin Lab 2002;48:5-18.

9. Zileli M, Kalayci M, Bașdemir G. Paraganglioma of the thoracic spine. J Clin Neurosci 2008;15:823-7.

10. Noorda RJ, Wuisman PI, Kummer AJ, Winters HA, Rauwerda JA, Egeler-Peerdeman SM. Non functioning malignant paraganglioma of the posterior mediastinum with spinal cord compression: A case report. Spine 1996;21:1703-9.

II. P Conti, H Mouchaty, B Spacca, AM Buccoliero, R Conti. Thoracic extradural paragangliomas: A case report and review of the literature. Spinal Cord 2006;44:120-5.

12. Pacak K, Eisenhofer G. An Assessment of Biochemical Tests for the Diagnosis of Pheochromocytoma. Nat Clin Pract Endocrinol Metab 2007;3:744-5.

13. Pacak K, Linehan WM, Eisenhofer G, Walther MM, Goldstein DS. Recent advances in genetics, diagnosis, localisation and treatment of pheochromocytoma. Ann Intern Med 200I; 134:315-26.

14. Shin JY, Lee SM, Hwang MY, Sohn CH, Suh SJ. MR findings of spinal paraganglioma: Report of three cases. J Korean Med Sci 200I;16:522-6.

15. Spector JA, Willis DN, Ginsburg HB. Paraganglioma (pheochromocytoma) of the posterior mediastinum: A case report and review of the literature. J Pediatr Surg 2003;38: I I 14-6.

16. Sundgren P, Annertz M, Englud E, Strombland LG, Holtas S. Paragangliomas of the spinal canal. Neuroradiology 1999;41:788-94. 